\title{
Endoscopic endonasal surgery for skull base tumours: technique and preliminary results in a consecutive case series report*
}

\author{
Joaquim Enseñat ${ }^{1}$, Matteo de Notaris ${ }^{1}$, Moises Sánchez1 ${ }^{1}$ Carla Fernández1', \\ Enrique Ferrer ${ }^{1}$, Manuel Bernal-Sprekelsen ${ }^{\$, 2}$, Isam Alobid ${ }^{\$, 2}$ \\ ' Department of Neurosurgery, Hospital Clinic de Barcelona, Faculty of Medicine, Universitat de Barcelona, Barcelona, Spain \\ ${ }^{2}$ Rhinology Unit, Department of Otorhinolaryngology, Hospital Clinic de Barcelona, Faculty of Medicine, Universitat de Barcelona, \\ Barcelona, Spain
}

Rhinology 51: 000-000, 2013 DOl:10.4193/Rhino12.090

*Received for publication: May 30, 2012

Accepted: October 16, 2012

\section{Summary}

Background: The introduction of the endoscope in transsphenoidal surgery has allowed access to lesions located in complex regions of the skull base under direct visual control. With the application of this technique, our group started treating pituitary tumours and from 2009 onwards began treating skull base lesions through extended endoscopic endonasal approaches.

The aim of the present study is to report our experience with extended endoscopic approaches. Indications, results, limitations and complications of this new technique are also discussed.

Material and methods: From January 2007 to January 2012, the endonasal approach was used in 40 patients with different cancerous lesions.

Results: Total tumour removal, as assessed by postoperative magnetic resonance imaging, occurred in 30/ 40 patients (75\%), but in 10 patients only partial removal was possible. Major complications, including cerebrospinal fluid leak, were observed in 5/40 patients (8\%). One patient died 3 months after surgery due to a severe systemic sepsis.

Conclusion: The extended endoscopic endonasal approach could be used as a minimally invasive and innovative technique for the removal of selected skull base lesions.

Key words: endonasal approach, endoscopy, extended approach, minimal invasive, transphenoidal approach, skull base

\section{Introduction}

In an attempt to approach complex skull base tumours, further advancement along the transsphenoidal route has enabled access to different areas around the sella. As a result of the experience gained in Endoscopic Sinus Surgery (ESS) over two decades ${ }^{(1,2)}$, the endoscope was first introduced for conventional transsphenoidal surgery and, thereafter, as the main visualizing tool throughout the whole procedure. This 'endoscopic endonasal approach' ${ }^{(3,4)}$ currently provides minimally invasive and adequate access to different skull base lesions. Recent anatomical studies ${ }^{(5-7)}$ and clinical reports ${ }^{(8-18)}$ have detailed and categorized this procedure into a series of anatomical modular approaches to the skull base, drawing on the pioneering, specialised and innovative work of Kassam, Carrau, and co-workers (10,19-21). 
In this field, the advent of new technologies such as high-resolution endoscopes, intraoperative neuronavigation systems and dedicated surgical instruments has provided the surgeon with excellent endonasal close-up visualization of the target area. Furthermore, recent advancement in endoscopic visual technology such as the three-dimensional (3D) endoscopes has greatly enhanced spatial perception ${ }^{(22)}$. This improved perspective allows better visual control and enables the surgeon to approach tumours located in these regions under direct control and with a wider and multi-angled view ${ }^{(23-26)}$.

The present study outlines our experience with the extended endoscopic endonasal approach (EEA). It provides clinical-functional findings, results and surgical complications observed in a consecutive series of 40 patients with skull base lesions.

\section{Materials and methods}

\section{Patients}

Over a 4-year period, a total of 44 procedures (4 patients needed a second surgical procedure) were performed. The series consisted of 19 males and 21 females, aged from 33 to 78 years (median 58 years).

All patients received the same follow-up using our postoperative care protocol: during the acute postoperative phase (1-2 weeks) speech and swallowing therapy, hormonal therapy (if needed) and physical rehabilitation were applied. Comprehensive postsurgical follow-up was carried out by the multidisciplinary surgical team (neurosurgeons and ENT surgeons) to evaluate the healing progress and to avoid any early general and approach-related complications. After the patient's discharge, routine periodic monitoring was considered necessary to assess recurrence of the primary pathology. This involved careful clinical evaluation and diagnostic imaging. Surgical results were evaluated by MRI and CT scans in all patients and classified according to the percentage of residual tumour.

The mean follow-up was 12 months (ranging from 6 to 36 months). Follow-up was done after surgery with clinical and imaging assessments according to each lesion. Postoperatively, an early 3-day MRI was used in the immediate follow-up for craniopharyngiomas, meningiomas, chordomas, chondrosarcomas and sinonasal tumours. For the other lesions, i.e pituitary adenomas, a standard follow-up was done at three months after surgery with MRI initially and then every 6 months to 1 year. Three main types of EEAs were performed: anterior skull base, clivus and cavernous sinus, as shown in Table 1.

Our series of 40 patients included: 2 olfactory groove, 1 planum sphenoidale, 3 tuberculum sellae and 2 petroclival meningiomas; 2 suprasellar, 2 cavernous sinus pituitary adenomas; 2 carcinomas of the nasal cavity; 5 craniopharyngiomas; 1 pilocytic astrocytoma; 7 chordomas; 2 squamous carcinoma; 2 chondrosarcomas; 1 mixofibrosarcoma, 1 fibrous dysplasia of the clivus; 2 cavum tumour extended to clivus; 2 neurofibromas; 1 skull base teratoma; 1 Rathke cleft cyst; 1 skull base sarcoma. Symptoms, pre- and post-operative endocrine function, ophthalmologic and otolaryngologic evaluation were recorded for all patients. Preoperative radiological investigations included brain MRI and paranasal CT scan. All patients underwent postoperative imaging in a conventional 3-month postoperative 1.5 Tesla MRI.

\section{Endoscopic equipment and instruments}

A 0-degree straight endoscope, $4 \mathrm{~mm}$ in diameter and $18 \mathrm{~cm}$ in length (Karl Storz Endoscopy, Tuttlingen, Germany) was used during the entire surgical procedure. Angled endoscopes $\left(30^{\circ}\right.$, $45^{\circ}$ ) were employed to achieve a'periscopical' view to control a proper removal of the lesion.

A digital endoscopic HD video camera provided clear endoscopic images. For the image and video documentation, a DVDbased recording HD system (AIDA - Karl Storz Endoscopy, Tuttlingen, Germany) integrated in an informatized operative room (OR1, Karl Storz Endoscopy, Tuttlingen, Germany) was employed. A full High Definition (HD) 16:9 flat monitor (1080p60) and a 300W Xenon light source complete the endoscopic set used during the procedures.

The use of image-guided systems such as a Neuronavigation System was required in almost every extended approach. The neuronavigator is put behind the head of the patient with the screen close to that of the endoscopic cart, providing the surgeon with a simultaneous view on both the screens.

The Intraoperative microDoppler ultrasonography system (Mizuho America, Beverly, MA, USA) represents a valid and reliable instrument to precisely locate the major vascular structures. A high-speed electric microdrill (Medtronic Midas rex Legend high speed drill) with an extra long and low profile handpiece, with diamond burr of small diameter (2-4mm) was employed for the craniotomy.

\section{Surgical technique}

In contrast to the standard endoscopic endonasal transsphenoidal approach to the sellar region, in which the sphenoidal sinus provides in the majority of cases the adequate surgical space, the extended approach requires some modifications aimed at increasing the work space as well as instrument manoeuvrability. In general, there are some common steps in all extended approaches.

After orotracheal intubation under general anesthesia, the patient is placed supine or in slight Trendelenburg's position on the operating table. To allow the use of the neuronavigation systems, the patient's head is put in the three-point Mayfield-Kees skeletal fixation headrest and turned $10^{\circ}-15^{\circ}$ on the horizontal plane, towards the surgeon. On the sagittal plane, accordingly with the type approach, the head is extended or flexed about 10-15 degrees. In the case of anterior cranial base approach, the 
Table1. Type of lesion and anatomical region approached through the extended endoscopic endonasal approach.

\begin{tabular}{|c|c|c|c|}
\hline $\begin{array}{l}\text { Extended endonasal ap- } \\
\text { proach }\end{array}$ & Diagnosis & Patients & Cases Operations \\
\hline Transcribiform & Olfactory groove meningioma & 2 & 3 \\
\hline Transcribiform & Rhinosinusal carcinoma & 2 & 2 \\
\hline Transtuberculum/transplanum & Planum sphenoidale meningioma & 1 & 1 \\
\hline Transtuberculum/transplanum & Craniopharyngioma & 5 & 6 \\
\hline Transtuberculum/transplanum & Skull base sarcoma & 1 & 1 \\
\hline Transtuberculum & Tuberculum sellae menignioma & 3 & 3 \\
\hline Transtuberculum & Rathke cleft Cyst & 1 & 1 \\
\hline Transtuberculum & Suprasellar adenoma & 1 & 1 \\
\hline Transtuberculum & Pilocytic astrocytoma & 1 & 1 \\
\hline Transclival & Clival chordoma & 6 & 8 \\
\hline Transclival & Chondrosarcoma & 2 & 2 \\
\hline Transclival & Mixofibrosarcoma & 1 & 1 \\
\hline Transclival & Fibrous dysplasia & 1 & 1 \\
\hline Transclival & Petroclival meningioma & 2 & 2 \\
\hline Transclival & Cavum tumor extended to clivus & 2 & 2 \\
\hline Transclival & Squamous carcinoma & 2 & 2 \\
\hline Ethmoid-pterygoid-sphenoid & Cavernous sinus Pituitary adenoma & 2 & 2 \\
\hline Ethmoid-pterygoid-sphenoid & Neurofibroma & 1 & 1 \\
\hline Ethmoid-pterygoid-sphenoid & Cavernous sinus chordoma & 1 & 1 \\
\hline Transorbital & Neurofibroma & 1 & 1 \\
\hline Skull base teratoma & Transpalatal & 1 & 1 \\
\hline
\end{tabular}

head is extended further to provide a more anterior trajectory and to avoid endoscope and instruments hitting the patient's trunk. In the case of transclival approach the head is more flexed because the route trajectory is inferior and directed downward. Usually a bilateral middle turbinectomy is performed in the majority of cases. Later, a vascular pedicled nasoseptal flap (Hadad flap) based on the nasoseptal artery is carried out and stored in the maxillary sinus ${ }^{(27)}$. We prefer to place this flap in the maxillary sinus to minimize possible visual interference of the target area. The posterior part of the septum is then drilled out. A wide anterior sphenoidotomy and a bilateral ethmoidectomy are later performed to identify the most important anatomical landmarks within the sphenoid bone: the sellar floor, the sphenoid planum, medial and lateral optocarotid recesses, the clival indentation and laterally, the bony prominences of the intracavernous carotid arteries and the optic nerves.

In fact, the exposure gained through an extended approach is 'tailored' depending on surgical pathway, type, tumour size and shape, and relationship with the surrounding neurovascular structures. The anatomical limits of the surgical box are definitively established using the microdoppler probe and the intraoperative neuronavigation system.

\section{Anterior skull base approaches}

Transtuberculum/Transplanum approach: The suprasellar region and the sphenoid planum are reached via a more anterior trajectory compared to that used for the sellar region. The bone removal starts with the opening of the upper two-thirds sella and the thinning of the tuberculum sellae, using a microdrill with a 2-mm diamond burr to expose the superior intercavernous sinus. Injury of this sinus during such manoeuvres could result in severe venous bleeding and is adequately controllable with haemostatic agents (Floseal or Surgicel) and gentle pressure with cottonoids. Two horizontal dural incisions are made a few millimetres above and below the sinus, which is then coagulated by bipolar forceps and cut with microscissors.

The tuberculum sellae is freed from the two medial opto-carotid recesses and from the planum sphenoidale, and is gently dissected from the dura and removed. A 2-mm Kerrison's rongeur is used to complete the removal of the bone up to the falciform ligament and posterior etmoidal arteries, which are a useful landmarks representing the anterior limit of the bony and dural opening.

The surgical field boundaries are represented anteriorly by the falciform ligament and the two posterior ethmoidal arteries; 
Table 2. Preoperative symptoms, resection and outcome for each patient. Complete resection in 23 patients, subtotal in 7 , partial in 10.

\begin{tabular}{|c|c|c|c|c|c|}
\hline Diagnosis & $\begin{array}{l}\text { Preoperative } \\
\text { symptoms }\end{array}$ & Resection & $\begin{array}{l}\text { Postoperative } \\
\text { complications }\end{array}$ & $\begin{array}{l}\text { Clinical } \\
\text { improvement }\end{array}$ & Reoperation \\
\hline Olfactory groove meningioma & Behaviour disorder & Complete & None & Yes & No \\
\hline Olfactory groove meningioma & $\begin{array}{l}\text { Visual deficit } \\
\text { Anosmia }\end{array}$ & Partial & CSF leak & Yes & Yes \\
\hline Planum sphenoidale meningioma & Visual deficit & Complete & $\begin{array}{l}\text { CSF leak } \\
\text { Meningitis } \\
\text { Hydrocephalus }\end{array}$ & Yes & No \\
\hline Tuberculum sellae meningioma & Visual deficit & Subtotal & No & No & No \\
\hline Tuberculum sellae meningioma & Visual deficit & Subtotal & No & No & No \\
\hline Tuberculum sellae meningioma & Visual deficit & Complete & No & Yes & No \\
\hline Petroclival meningioma & Visual deficit & Subtotal & No & Yes & No \\
\hline Petroclival meningioma & VI cranial nerve palsy & Partial & No & No & No \\
\hline Suprasellar macroadenoma & Visual deficit & Subtotal & $\begin{array}{l}\text { Hydrocephalus } \\
\text { Sepsis } \\
\text { Convulsive status }\end{array}$ & Death & No \\
\hline Suprasellar macroadenoma & Optic neuropathy & Complete & $\begin{array}{l}\text { Transient } \\
\text { diabtes insipidus }\end{array}$ & No & No \\
\hline Rhinosinusal carcinoma & Anosmia & Complete & None & No & No \\
\hline Rhinosinusal carcinoma & Anosmia & Complete & None & No & No \\
\hline Craniopharyngioma & Bitemporal hemianopia & Partial & $\begin{array}{l}\text { Transient } \\
\text { diabtes insipidus }\end{array}$ & Yes & No \\
\hline Craniopharyngioma & Headache & Complete & CSF leak & Yes & No \\
\hline Craniopharyngioma & Panhypopituitarism & Partial & None & No & Yes \\
\hline Craniopharyngioma & Visual deficit & Complete & None & Yes & No \\
\hline Craniopharyngioma & None & Complete & None & No & No \\
\hline Pilocytic astrocytoma & Visual deficit & Partial & None & No & No \\
\hline Clivus chordoma & $\begin{array}{l}\text { Visual deficit } \\
\text { VI cranial nerve palsy }\end{array}$ & Partial & None & Yes & Yes \\
\hline Clivus chordoma & Visual deficit & Complete & None & Yes & No \\
\hline Clivus chordoma & VI cranial nerve palsy & Complete & $\begin{array}{l}\text { Transient } \\
\text { diabetes insipidus }\end{array}$ & No & No \\
\hline Clivus chordoma & VI nerve palsy & Subtotal & None & Yes & No \\
\hline Petroclival chordoma & XII nerve palsy & Partial & CSF leak & Yes & No \\
\hline Petroclival chordoma & III nerve palsy & Partial & None & No & No \\
\hline Cavernous chordoma & VI nerve palsy & Complete & None & No & No \\
\hline Squamous carcinoma & III nerve palsy & Complete & None & Yes & No \\
\hline Squamous carcinoma & Anosmia & Subtotal & None & No & No \\
\hline Chondrosarcoma & $\begin{array}{l}\text { VI and VII cranial nerve palsy } \\
\text { Hearing loss }\end{array}$ & Complete & $\begin{array}{l}\text { None } \\
\text { CSF leak }\end{array}$ & No & No \\
\hline Chondrosarcoma & VI cranial palsy & Complete & None & No & No \\
\hline Mixofibrosarcoma & VI cranial nerve palsy & Subtotal & None & No & No \\
\hline Fibrous displasia of the clivus & Headache & Partial & None & No & No \\
\hline Cavum tumour extended to clivus & Radiological growth & Complete & None & No & No \\
\hline Cavum tumour extended to clivus & Radiological growth & Complete & None & No & No \\
\hline Cavernous sinus pituitary adenoma & Acromegaly & Complete & None & Cured & No \\
\hline Cavernous sinus pituitary adenoma & Acromegaly & Complete & $\begin{array}{l}\text { Transient } \\
\text { diabtes insipidus }\end{array}$ & Cured & No \\
\hline Cavernous sinus neurofibroma & Radiological growth & Complete & None & No & No \\
\hline Orbital neurofibroma & Radiological growth & Partial & None & No & No \\
\hline Skull base teratoma & Optic neuropathy & Complete & None & Yes & No \\
\hline
\end{tabular}


Table 2. Continued.

\begin{tabular}{llllcc}
\hline Diagnosis & $\begin{array}{l}\text { Preoperative } \\
\text { symptoms }\end{array}$ & Resection & $\begin{array}{l}\text { Postoperative } \\
\text { complications }\end{array}$ & $\begin{array}{c}\text { Clinical } \\
\text { improvement }\end{array}$ & Reoperation \\
\hline Rathke cleft cyst & Optic neuropathy & Complete & CSF leak & No & No \\
Skull base sarcoma & None & Complete & None & No & No
\end{tabular}

posteriorly by the upper half of the sella; and laterally by the medial aspect of the opto-carotid recesses.

Transcribriform approach: This route represents the rostral extension of the previous approach, from the anterior part of the planum until the posterior wall of the frontal sinuses. In this case, passing through the anterior and posterior ethmoid is mandatory. The bulla ethmoidalis, the suprabullar recess and the posterior ethmoid are opened to expose the lamina papyracea laterally, the floor of the anterior cranial base superiorly, and the superior part of the posterior nasal septum. The latter is removed to allow wide exposure of the contralateral skull base. Finally, the superior portion of the lamina papyracea is removed from the medial aspects of the orbits, thus exposing the anterior and posterior ethmoidal arteries. The limits of this approach are: anteriorly, the back wall of the frontal sinuses; laterally, the medial wall of the orbits; and posteriorly, the anterior part of the planum sphenoidale at the level of the posterior ethmoidal arteries. In such cases, these arteries must be coagulated to obtain an early devascularization of the tumour.

The clival approach: Access to the clivus is achieved via a more caudal trajectory than is necessary for accessing the sellar region. The nasal mucosa is bilaterally dissected from the vomer, along the inferior wall of the sphenoid sinus, approximately $5 \mathrm{~mm}$ lateral to vomero-sphenoid junction (VSJ), identifying the Vidian canals, which represent the lateral limits of the surgical corridor ${ }^{(28)}$. The vomer and the inferior wall of the sphenoid sinus are completely removed, thus exposing the sphenoidal and rhinopharyngeal part of the clivus. At this point, the clivus is disclosed from the level of the pituitary gland up to the level of the Eustachian tubes. According to the lesion extension, the clival bone is more or less extensively drilled with a microdrill. The limits of the clival fenestration are represented by the sella superiorly and by the paraclival segments of the intracavernous carotid artery laterally, the inferior limit being dependent on the lesion extension. In the case of intradural lesions, venous bleeding from the basilar plexus must be controlled with haemostatic agent before the dural opening, paying attention to preserve the abducent nerve. Venous bleeding from the basilar plexus can be controlled through gentle pressure with a haemostatic agent, such as Gelfoam soaked in thrombin followed by coverage with a cottonoid. The opening of the paraclival carotid protuberances depends on the characteristics and the extension of the lesion.

The cavernous sinus approach: The procedure starts with a middle turbinectomy and an anterior and posterior ethmoidectomy in the same site of the lesion. In the case of bilateral cavernous sinus extension of the lesion, bilateral removal of the mentioned nasal structures is mandatory. A wide sphenoidotomy is then performed to expose the main landmarks over the posterior wall of the sphenoid sinus. To reach the lateral recess of the sphenoid sinus and to improve instrument manoeuvrability the medial pterygoid process is drilled out. The sella is then opened using a microdrill with a 2-mm diamond burr. The drilling is extended laterally to expose the carotid prominence at the level of the parasellar tract of the internal carotid artery and the anterior wall of the cavernous sinus. The opening of the dura can be carried out medially or laterally to the internal carotid artery, depending on the consistency and extension of the lesion.

\section{Skull base reconstruction}

After any endoscopic endonasal extended skull base approach, a relatively extensive osteodural defect has to be reconstructed at the end of the procedure. In particular, a watertight reconstruction is the key to preventing any complications related to post-operative CSF leakage. One single large layer of dural substitute is positioned in the extradural space, covering the dural opening. A sized sheath of resorbable solid material (LactoSorb, Lorenz Surgical, Jacksonville, FL, USA) is then overlapped to the layer of the dural substitute and positioned in the intradural space. In this manner, a solid barrier between the intra and extradural compartments is created. Once a watertight barrier has been achieved, the vascularized nasoseptal pedicled flap is used to cover the skull base reconstruction. This technique consists of the use of a septal-nasal flap of mucoperiosteum and mucoperichondrium vascularized by the posterior septal artery (27). Vascularized mucosal flaps have been used in most of the procedures with some exceptions. This technique may not be a viable option for reconstruction of very anterior fossa defects, when the pathology involves septal mucosal tissue, or if the sphenoid rostrum is affected by malignancy. In such cases, if the tumour is confined to the extradural space and intraoperative 


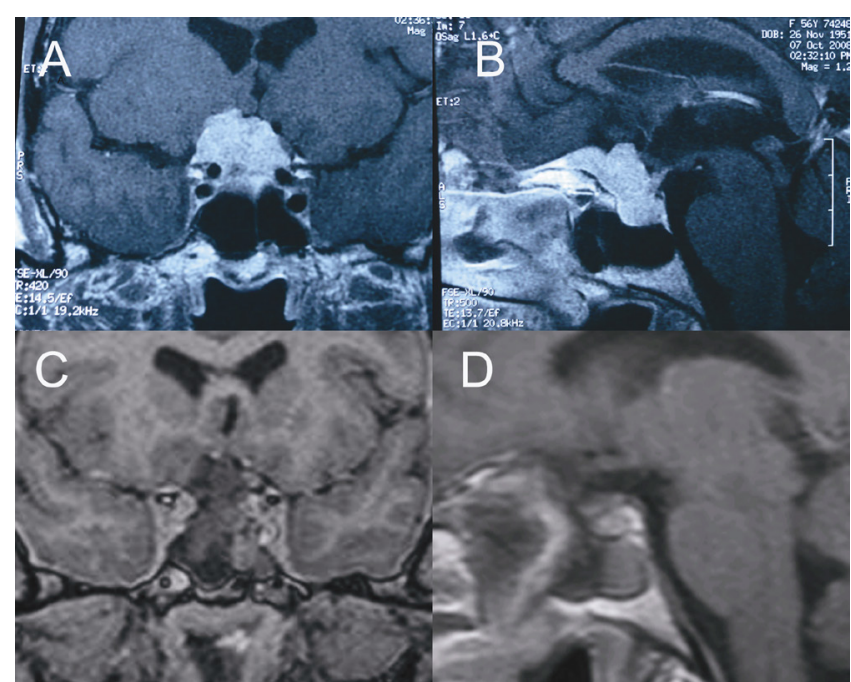

Figure 1. Tuberculum sellae meningioma. Pre-operative T1-weighted coronal (A) and sagittal (B) axial MRI with gadolinium enhancement. Post-operative T1-weighted coronal (C) and sagittal (D) MRI with gadolinium enhancement showing the complete resection the lesion.

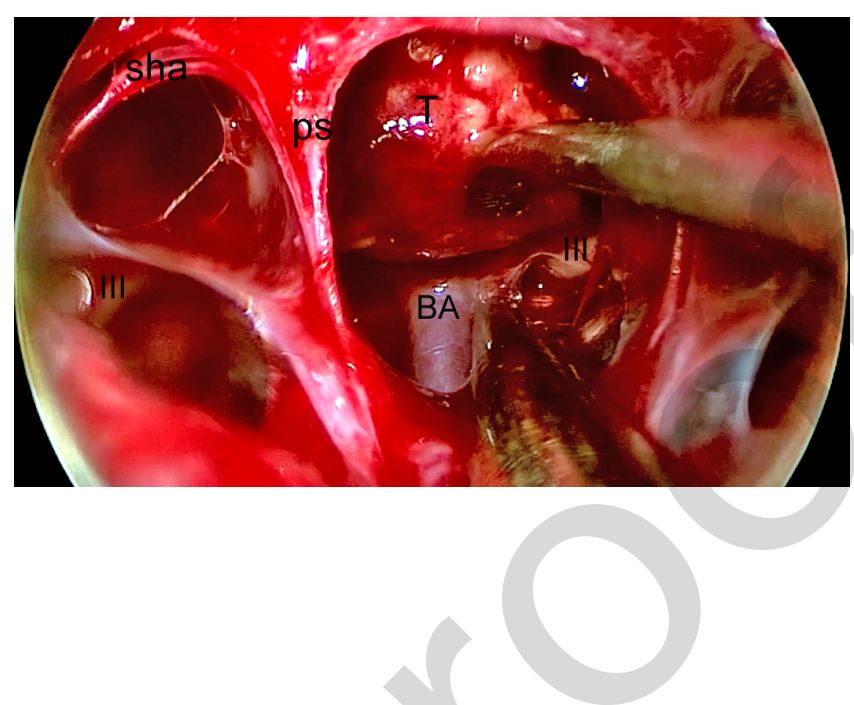

Figure 2. Infunbular craniopharyngioma, subchiasmatic route. T:tumour, P1: posterior cerebral artery; BA: basilar artery; sha: superior hypophyseal artery; ps: pituitary stalk, pg: pituitary gland; III: oculomotor nerve.

CSF is observed, or in the case of brain or meningeal invasion, an intra-extradural reconstruction is performed. According to this method, a thin layer of fibrin glue (Tissucol ${ }^{\circledR}$ Baxter, Vienna, Austria) or a small fat graft is positioned in the intradural space as a first barrier to CSF and to fill the dead space. The closure of the osteo-dural defect is then achieved, using a combination of a solid buttress material such as a dural substitute as previously described ${ }^{(29)}$.

In the majority of cases, a lumbar drain is positioned preoperatively and removed days after the surgery. Anterior nasal packing is maintained 24 - 48 hours after surgery and treatment with antibiotics is prolonged until the lumbar drain is removed. In only two cases (a suprasellar macroadenoma and a sphenoidal planum meningioma), the bone defect reconstruction was completed using exclusively a dural substitute inlay and the Hadad flap overlay without using a postoperative lumbar drain.

\section{Results}

From our point of view, the value of the extended endoscopic endonasal approaches offers an adequate and satisfactory option in selected skull base lesions. All the data, including symptoms, resection, postoperative complications and clinical outcome after surgery, are collated in Table 2. Complete removal ( $0 \%$ residual) was achieved in $23 / 40$ (57.5\%) patients, subtotal removal (<20\% residual) in $7 / 40$ (17.5\%) patients, and partial removal (> 20\%) in 10/40 (25\%) patients.

With regards to the preoperative status, visual deficit (visual acuity loss or visual field defect) was the most frequent symptom. Moreover, within the cranial nerves, the sixth was the most frequently affected or compressed by the lesion.

In the case of nasal complications, mild epistaxis occurred in $4 \%$ of patients in the immediate postoperative period. This was solved with nasal packing for 48 hours. In the postoperative period, the mean time to absence of crusting was $99 \pm 16$ days (range 75 - 121 days) in the case of nasoseptal flap, and mean time to septum remucosalization was $87 \pm 14$ days. Late complications of the nasal sinuses, mainly represented by synechiae and adhesions without subjective breathing difficulties, were present in $8 \%$ of patients. Moderate-to-severe smell loss (Visual Analogue Scale $>30 \mathrm{~mm}$ ) was reported in $45 \%$ of study patients.

In relation to anterior cranial base pathology, two of the three meningiomas (Figure 1) and both nasal carcinomas were completely removed. Subtotal resection was achieved in the suprasellar adenoma and in two of the tuberculum meningiomas. Three of the five craniopharyngiomas were completely removed (Figure 2), and in the other two cases the risk of morbidity due to tumour consistency was deemed to be too high to carry out total removal of the lesions.

Complete resection was obtained in the three chordomas and two chondrosarcomas. Complete resection was also achieved in the two patients with nasopharyngeal tumour who underwent surgery for local recurrence; both remain stable. One of the chordomas was subtotally resected (Figure 3). The patient with mixofibrosarcoma was reoperated on at three months in addition to the subtotal resection because of the fast growth of the tumour; radiotherapy was postoperatively administered. Partial 


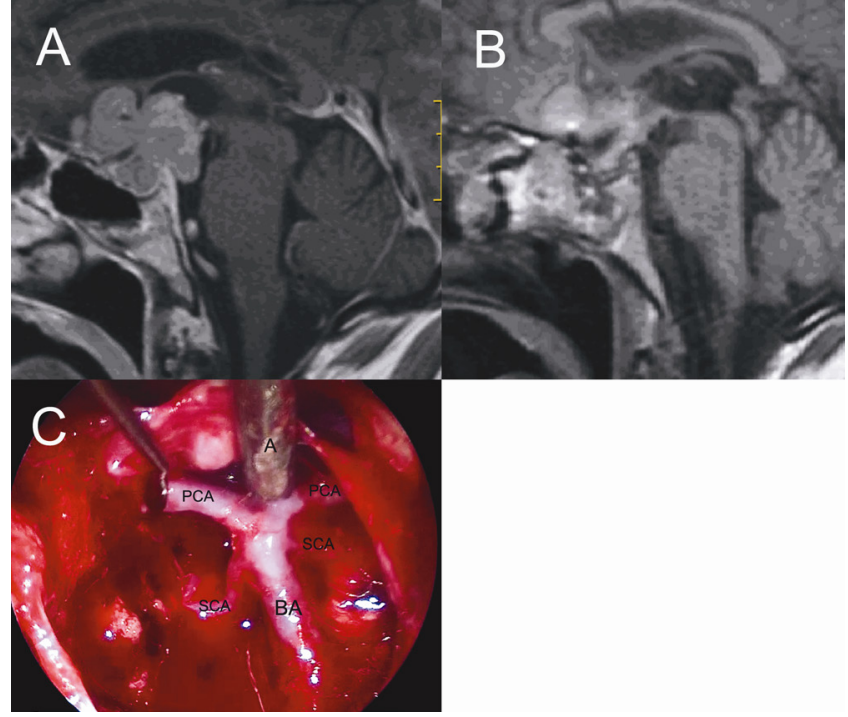

Figure 3. Clivus chordoma: Pre-operative T1-weighted sagittal (A) MRI with gadolinium enhancement. Post-operative sagittal (B) T1-weighted MRI with gadolinium enhancement showing a subtotal resection of the lesions. (C) Intraoperative image showing the most important vascular structures: SCA: superior cerebellar artery; BA: basilar artery; PCA: posterior cerebral artery; A: aspirator.

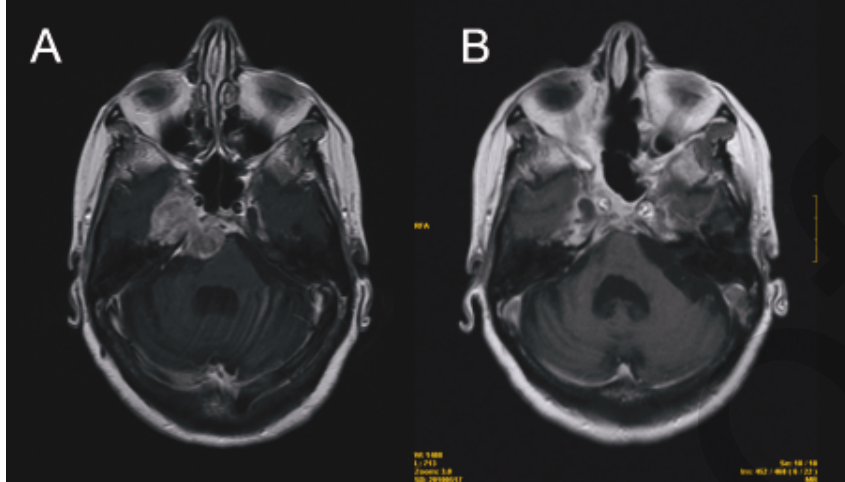

Figure 4. Chondrosarcoma: Pre-operative T1-weighted axial (A) MRI with gadolinium enhancement. Post-operative axial (B) T1-weighted MRI MRI with gadolinium enhancement showing the complete resection the lesion. resection was achieved in both the third chordoma and fibrous dysplasia cases. As regards the two petroclival meningiomas, a partial and a subtotal resection was achieved due to the tumour consistency.

Both pituitary adenomas that extended to the cavernous sinus were completely removed using an ethmoido-pterygo-sphenoidal approach. Acromegaly was cured in both patients, according to oral glucose tolerance test and free IGF-I levels also rapidly normalized. One cavernous neurofibroma was completely removed, while the orbital one at a location level to the posterior medial wall of the orbit was very firm and only partially debulked. The rathke cleft cyst was completely removed and the cyst wall was communicated widely with the subarachnoid space.

The patient with the giant skull base teratoma was a 2-month child operated on through a combined endoscopic endonasal and transplatal approach; complete resection was achieved.

Visual deficit improved in all patients but one. Sixth cranial nerve deficit was improved in only one patient.

Recurrence is shown in Table 1: a total of 4 patients (10\%) had clinical and neuroradiological recurrence: 1 olfactory groove meningioma, 1 craniopharyngioma, 1 clivus chordoma and 1 petroclival chordoma.
The vascularized nasoseptal flap has been utilized in all procedures except in the case of sinonasal malignancies (Figure 5). Postoperative cerebrospinal fluid leak was present in 5/40 patients (8\%). Two patients with a planum sphenoidale and an olfactory groove meningioma were operated on respectively through a transtuberculum/tranplanum and a transcribrifrom approach. The other three patients, one with a suprasellar craniopharyngioma and two with chordoma and chondrosarcoma, were operated on via an endonasal approach that extended to the clivus. Postoperative lumbar drainage was placed by only 2 of these 5 patients. Concerning the patient with suprasellar adenoma extending to the third ventricle, we believe that, in selected cases of giant pituitary adenomas with ventricular extension, the transsphenoidal route may help to achieve a gross total removal, thereby avoiding the need for a staged procedure. A second transcranial or combined endonasal/ transcranial surgery can be considered as a second option in the event of partial resection. Unfortunately, after the endoscopic procedure, this patient developed several complications. A sudden hyponatremia accompanied by loss of consciousness and seizures after postoperative day 2 lead to bronchoaspiration and severe sepsis. All attempts to revive the patient failed to lead to clinical improvement. On postoperative day 3 the patient had an occipital stroke, convulsive status and died several days after surgery. 


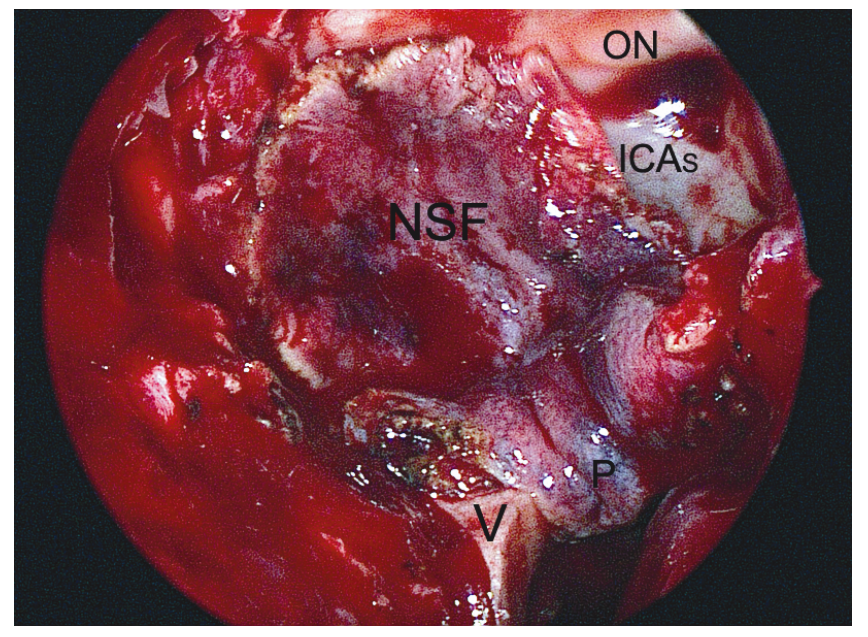

\section{Discussion}

The transsphenoidal route has been used for a century for the resection of pituitary and other sellar tumours. In the past decade, however, the endoscopic endonasal transsphenoidal approach has been proposed as a minimally invasive procedure for the treatment of pathologies of the sellar region. This procedure presents various advantages compared to the traditional transsphenoidal microsurgical approach, such as an improved vision of the surgical field, less traumatism of the nasal structures and reduced complications. Patients' quick recovery, short hospital stays and minimal postoperative discomfort have also been reported in the pertinent literature. More recently, the standard endoscopic endonasal technique has been extended to provide access to a variety of skull base lesions around the sellar region. Indeed, the sella turcica, which could be considered to constitute the centre of the skull base, is commonly impinged upon by lesions that arise from it and extend to the perasellar areas or, on the contrary, by lesions starting from other areas of the skull base and with intrasellar extension. In fact, given Weiss's pioneering work since $1987^{(30)}$, the sellar area can now be considered the starting point to extend the transsphenoidal approach to the anterior, middle and posterior skull base.

More recently, the wider and panoramic field of vision offered by the endoscope has boosted the development of a variety of modifications of the transsphenoidal approach, targeted mainly at the entire skull base from the most anterior areas to the craniovertebral junction and adjacent regions. Indeed, this approach has been supported by important diagnostic and technical contributions, such as: frameless neuronavigation, doppler ultrasonography, intraoperative magnetic resonance, and high definition and 3D endoscope cameras.

Significant controversies remain as to the indications for the approach to the cranial base tumours using this extended approach from below. Since the craniotomy is the dominant approach
Figure 5. The vascularized nasoseptal flap, utilized in all procedures. NSF: naso septal flap, ICAs: sellar segment of the internal carotid artery; ON: left optic nerve; V: vomer; P: pedicle of the flap. with good results in terms of radicality of tumour resection, with good outcome and low complications rates ${ }^{(31)}$, endonasal techniques are required to provide at least equivalent results. The neurosurgeon should apply this thinking on an individual basis for each patient ${ }^{(32)}$. The transcranial and the transsphenoidal route should be considered two complementary options at the surgeon's disposal to enable access to the target; one does not exclude the other. We completely agree with Prof. Ciric's philosophy when he stated in a published paper ${ }^{(33)}$ : "a virtuoso is one who knows the relevant anatomy perfectly, correctly applies microsurgical technique, masters endoscopic skills, finds the optimal solution to specific surgical problems, and applies wise judgment, with consummate respect for his or her patients."

Finally, the authors think that the limitations of the EEA have yet to be fully established. Until recently, the development of endonasal skull base surgery was limited by technology and anatomical knowledge of the entire skull base from an inferior perspective. More recently, after great advancements in this field, other important limitations of endoscopic surgery include the history of the patient, nature and the location of the pathology, neurovascular relationships, surgeon experience as well as the institutional resources ${ }^{(34)}$. Regarding our learning curve, a retrospective analysis of our practice during the transition period between the use of the microscopic and the pure endoscopic technique for sellar and parasellar lesions convinced our group to convert to a fully endoscopic procedure, since we found that the endoscope improved our ability to differentiate normal pituitary gland from tumour. It also provided better exposure of parasellar lesions. Our early results showed that the fully endoscopic procedure results in improved rates of complete tumour removal, easier patient recovery and a shorter hospital stay when compared to our microscopic series ${ }^{(24)}$. For such reasons, since 2009, our group has started to treat selected skull base lesions through extended endoscopic endonasal approaches according to the basic concepts and principles of endonasal 
oncological surgery introduced by Kassam et al. ${ }^{(35)}$.

This does not mean that the value of the microsurgical techniques has been undermined or even abandoned; indeed during the same period, a total of 12 skull base lesions have been operated on using transcranial skull base approaches. As a matter of fact, we used a bilateral subfrontal approach to operate on 2 huge olfactory groove meningioma's extending laterally to the medial wall of the orbits. A standard pterional approach has been utilized to operate on 2 tuberculum sellae meningiomas with anterior cerebral artery encasement. Two craniopharyngiomas extending into the third ventricle were successfully removed through a frontolateral trans-lamina terminalis approach. While 1 clival condrosarcoma extending to the middle fossa was partially removed through a frontotemporozigomatic approach. Finally, a combined endonasal and transcranial route has been used to approach different sinonasal pathologies with brain and meningeal invasion and to ensure an adequate skull base reconstruction: 3 squamous cell carcinomas, 1 esthesioneuroblastoma, 1 undifferentiated carcinoma and 1 adenocarcinoma.

In our opinion, the choice of the surgical approach depends on many factors such as the size, the extension and the nature of the lesion and, above all, the experience of the surgeon. As such, and given the complexity of the decision-making process, the resectability of some types of tumours located in certain anatomic areas remains an open question.

Our reduced series do not enable us to draw definitive conclusions. Significant lateral extension over the medial wall of the orbit, encasement of neurovascular structures, and subpial tumour invasion into the brain cortex still represent a clear contraindication. In contrast, for tuberculum sellae meningiomas, a lateral invasion of the tumour into the optic canal is not considered a general contraindication for EEAs. Regarding clival lesions, as already described by Kassam et al., (21), the main principle is to avoid crossing nerves. The transclival approach is used to access tumours ventral to cranial nerves; if there is dorso-lateral extension, alternative approaches should be considered.

Another important issue with regard to the surgical complica- tions is postoperative CSF leak. Indeed, in the early stages of endoscopic surgery for sellar lesions, the highest percentage of CSF leak occurred during the first 60 cases ${ }^{(36)}$. The same level of incidence has been observed with the present series. On the basis of experience gained in the last years, some modifications of our surgical strategy to prevent CSF leak has been changed over the time. For the first cases of skull base tumours, we decided to use the lumbar drain and nasal packing in every patient for at least the first five days after the operation. Now we use lumbar drain only in high-risk patients, mainly suprasellar tumours extending into the third ventricle, for at least two days after surgery. Another crucial point concerning our learning curve was the opportunity we had of performing immersive laboratory cadaver dissection at our institution ${ }^{(7)}$. This has been fundamental to our surgical skills acquisition.

\section{Conclusion}

In our opinion, the value of the extended endoscopic endonasal approaches for different pathological conditions offers an adequate and satisfactory option in selected skull base lesions. With regards to complications, the technique is sufficiently safe and it can be said that the frequency of major complications is quite rare in expert hands. The problem of postoperative CSF leak is being addressed with novel and effective repair techniques. This study demonstrated that EEA may redefine the way some lesions could be managed in the future.

\section{Authorship contribution}

$J E$ : Execution of experiments and design of research

MdN: Design of research and wrote the paper

MS: Execution of experiments

CF: Design of research and wrote the paper

EF: Design of research

MB-S: Execution of experiments

IA: Execution of experiments, design of research and wrote the paper

\section{Conflict of interest}

The authors declare that they have no conflicting interests.

\section{References}

1. Kennedy DW. Functional endoscopic sinus surgery. Technique. Arch Otolaryngol. 1985; 111:643-649.

2. Stammberger $\mathrm{H}$, Posawetz W. Functional endoscopic sinus surgery. Concept, indications and results of the Messerklinger technique. Eur Arch Otorhinolaryngol. 1990; 247: 63-76

3. Cappabianca P, Alfieri A, de Divitiis E Endoscopic endonasal transsphenoidal approach to the sella: towards functional endoscopic pituitary surgery (FEPS). Minim Invasive Neurosurg. 1998; 41: 66-73.

4. Carrau RL, Jho HD, Ko Y. Transnasaltranssphenoidal endoscopic surgery of the pituitary gland. Laryngoscope. 1996; 106: 914-918.

5. Cavallo LM, Cappabianca P, Galzio R, laconetta G, de Divitiis E, Tschabitscher M. Endoscopic transnasal approach to the cavernous sinus versus transcranial route: anatomic study. Neurosurgery. 2005; 56 (2 Suppl): ONS379-ONS89.
6. Kassam AB, Vescan AD, Carrau RL, et al. Expanded endonasal approach: vidian canal as a landmark to the petrous internal carotid artery. J Neurosurg. 2008; 108: 177-183.

7. de Notaris M, Solari D, Cavallo LM, et al. The Use of a Three-Dimensional Novel Computer-Based Model for Analysis of the Endonasal Endoscopic Approach to the Midline Skull Base. World Neurosurg. 2011; 75: 106-113.

8. Cappabianca P, Cavallo LM, Esposito F, de Divitiis O, Messina A, de Divitiis E. 
Extended endoscopic endonasal approach to the midline skull base: the evolving role of transsphenoidal surgery. In: Pickard JD, Akalan N, Di Rocco C, Dolenc VV, Lobo Antunes J, Mooij JJA, et al., editors. Advances and Technical Standards in Neurosurgery. Wien New York: Springer 2008. p. 152-99.

9. Kassam AB, Gardner PA, Snyderman CH, Carrau RL, Mintz AH, Prevedello DM. Expanded endonasal approach, a fully endoscopic transnasal approach for the resection of midline suprasellar craniopharyngiomas: a new classification based on the infundibulum. J Neurosurg. 2008; 108 : 715-728.

10. Kassam AB, Mintz AH, Gardner PA, Horowitz MB, Carrau RL, Snyderman CH. The expanded endonasal approach for an endoscopic transnasal clipping and aneurysmorrhaphy of a large vertebral artery aneurysm: technical case report. Neurosurgery. 2006; 59 (1 Suppl 1): ONS162-ONS5.

11. Jho HD, Ha HG. Endoscopic endonasal skull base surgery: Part 1--The midline anterior fossa skull base. Minim Invasive Neurosurg. 2004; 47: 1-8.

12. Jardeleza C, Seiberling K, Floreani S, Wormald PJ. Surgical outcomes of endoscopic management of adenocarcinoma of the sinonasal cavity. Rhinology. 2009; 47: 354-361.

13. Frank G, Pasquini E. Endoscopic endonasal approaches to the cavernous sinus: surgical approaches. Neurosurgery. 2002; 50: 675.

14. de Divitiis E, Cappabianca P, Esposito F, Cavallo LM, de Divitiis O. Tuberculum sellae meningiomas: High route or low route? Presentation of a series of 51 consecutive cases. Neurosurgery. 2008; 62: 556-563.

15. Castelnuovo P, Dallan I, Bignami M, et al. Nasopharyngeal endoscopic resection in the management of selected malignancies: ten-year experience. Rhinology. 2010; 48: 84-89.

16. Lund VJ, Stammberger $H$, Nicolai $P$, Castelnuovo P, Beal T, Beham A, et al. European position paper on endoscopic management of tumours of the nose, paranasal sinuses and skull base. Rhinology. 2010 (Suppl 22): 1-143.

17. Kurschel S, Gellner V, Clarici G, Braun H, Stammberger $\mathrm{H}$, Mokry M. Endoscopic rhino-neurosurgical approach for nonadenomatous sellar and skull base lesions. Rhinology. 2011; 49: 64-73.

18. Batra PS, Luong A, Kanowitz SJ, et al. Outcomes of minimally invasive endoscopic resection of anterior skull base neoplasms. Laryngoscope. 2010; 120: 9-16.
19. Kassam AB, Prevedello DM, Thomas A, et al. Endoscopic endonasal pituitary transposition for a transdorsum sellae approach to the interpeduncular cistern. Neurosurgery. 2008; 62 (3 Suppl 1): 57-72; discussion -4.

20. Kassam AB, Prevedello DM, Carrau RL, et al. The front door to meckel's cave: an anteromedial corridor via expanded endoscopic endonasal approach- technical considerations and clinical series. Neurosurgery. 2009;64 (3 Suppl): 71-82.

21. Stippler M, Gardner PA, Snyderman $\mathrm{CH}_{\text {, }}$ Carrau RL, Prevedello DM, Kassam AB. Endoscopic endonasal approach for clival chordomas. Neurosurgery. 2009; 64: 268 277.

22. Roth J, Singh A, Nyquist G, et al. Threedimensional and 2-dimensional endoscopic exposure of midline cranial base targets using expanded endonasal and transcranial approaches. Neurosurgery. 2009; 65: 1116 1128.

23. Ensenat J, Ortega A, Topcewski T, et al. Predictive value of the Knosp classification in grading the surgical resection of invasive pituitary macroadenomas. A prospective study of 23 cases. Neurocirugia (Astur). 2006; 17: 519-526.

24. Ensenat J, Quesada JL, Aparicio J, Pamies C, Barber X, Topczewski T, et al. Prospective comparative study on 50 patients between microsurgical sublabial transsphenoidal approach and endoscopic endonasal transsphenoidal approach. Neurocirugia (Astur) 2009; 20: 335-344.

25. Ensenat J, Alobid I, de Notaris $M$, et al Endoscopic endonasal clipping of a ruptured vertebral - posterior inferior cerebellar artery aneurysm. Technical case report. Neurosurgery 2011; 69 (1 Suppl Operative) ONS121-127.

26. Samara L, Alobid I, Ensenat J, De Notaris M, Bernal-Sprekelsen M. Neurosurgeonotolaryngologist collaboration in endonasal approaches to the clivus and suprasellar region. B-ENT. 2011; 7 Suppl 17: 33-39.

27. Kassam AB, Thomas $A$, Carrau $R L$, Snyderman $\mathrm{CH}$, Vescan $\mathrm{A}$, Prevedello $\mathrm{D}$, et al. Endoscopic reconstruction of the cranial base using a pedicled nasoseptal flap. Neurosurgery. 2008; 63 (1 Suppl 1): ONS4452.

28. de Notaris M, Cavallo LM, Prats-Galino A, et al. Endoscopic endonasal transclival approach and retrosigmoid approach to the clival and petroclival regions. Neurosurgery. 2009; 65 (6 Suppl): 42-50; discussion -2.

29. Cavallo LM, Messina A, Esposito F, et al. Skull base reconstruction in the extended endoscopic transsphenoidal approach for suprasellar lesions. J Neurosurg. 2007; 107: 713-720.

30. Weiss $\mathrm{MH}$. The transnasal transsphenoidal approach. In: Apuzzo MLJ, editor. Surgery of the third ventricle. Baltimore: Williams \& Wilkins; 1987. p. 476-494.

31. Fahlbusch R, Honneger J, Buchfelder M. Transsphenoidal microsurgery for craniopharyngiomas. In: Schmidek HH, editor. Shmidek \& Sweet Operative neurosurgical techniques Indications, methods and results. Philadelphia: W. B. Saunders; 2000. p. 503-551.

32. Yasargil MG. Transcranial surgery for large pituitary adenomas. In: Yasargil MG, editor. Microneurosurgery: Microneurosurgery of CNS Tumors. Stuttgart: Georg Thieme Verlag; 1996. p. 200-207.

33. Ciric IS, Cozzens JW. Craniopharyngiomas: transsphenoidal method of approach--for the virtuoso only? Clin Neurosurg. 1980; 27: 169-187.

34. Snyderman CH, Pant $H$, Carrau RL, Prevedello D, Gardner P, Kassam AB. What are the limits of endoscopic sinus surgery? the expanded endonasal approach to the skull base. Keio J Med. 2009; 58: 152-160.

35. Prevedello DM, Kassam AB, Snyderman C, et al. Endoscopic cranial base surgery: ready for prime time? Clin Neurosurg. 2007; 54: 48-57.

36. Romero Adel C, Nora JE, Topczewski TE, Aguiar PH, Alobid I, Rodriguez EF. Cerebrospinal fluid fistula after endoscopic transsphenoidal surgery: experience in a spanish center. Arq Neuropsiquiatr. 2010; 68: 414-417

\author{
Isam Alobid \\ Rhinology Unit and Smell Clinic \\ Dept of Otorhinolaryngology \\ Hospital Clínic, Universitat de Barce- \\ lona \\ c/ Villarroel, 170 \\ Barcelona 08036 \\ Spain
}

Tel: +34-932-279 872

Fax: +34-932-275050

E-mail: ialobid@clinic.ub.es 